Lexis Vol. XLIV (1) 2020: 245-267

\title{
El castellano amazónico en la novela Paiche. Análisis dialectológico
}

\author{
Stefano Pau \\ Università di Cagliari
}

\section{RESUMEN}

Tomando como punto de partida las peculiaridades que caracterizan el castellano amazónico peruano en sus diversas variedades, este trabajo se propone un análisis dialectológico de la novela Paiche, del escritor y pintor César Calvo de Araújo. En primer término, se examinan las estrategias empleadas por el autor para condensar y reproducir en la obra las principales marcas del sistema fonológico, y, en segundo término, se analiza la dimensión morfosintáctica, dedicando especial atención a los aspectos relacionados con los posesivos y la discordancia nominal.

Palabras clave: Análisis morfosintáctico y fonético, castellano amazónico peruano, Paiche, Calvo de Araújo

Amazonian Castilian in the Novel Paiche. Dialectological Analysis

ABstract

Taking as a starting point the peculiarities that characterize the Peruvian Amazonian Spanish in its different varieties, this paper proposes a dialectological analysis of the novel Paiche by the writer and painter César Calvo de Araújo. Firstly, we examine the strategies used by the author to condense and reproduce the main items of the phonological system on the 
written page, and secondly, we analyze the morpho-syntactic dimension, paying special attention to the aspects related to the possessive and the nominal disagreement.

Keywords: Morpho-syntactic and phonetic analysis, Peruvian Amazonian Spanish, Paiche, Calvo de Araújo

\section{Introducción}

En este texto, se propone un análisis dialectológico de la novela Paiche, del escritor y pintor César Calvo de Araújo. En particular, se abordarán las dimensiones fonética, morfológica y sintáctica. El trabajo llevado a cabo ha permitido identificar la manera en la que el autor sincretiza y condensa algunos de los rasgos más característicos de las diversas variantes del castellano hablado en la Amazonía peruana.

En efecto, la lengua importada de Europa ha tenido, en la región oriental peruana, una evolución peculiar debido a múltiples factores (Escobar 1978: 75), entre los cuales destacan el aislamiento del resto del país, su condición periférica con respecto a los centros políticos y administrativos, los lazos con las regiones colindantes occidentales (los contactos con los lusohablantes de Brasil) y, sobre todo, el influjo a nivel de sustrato de las numerosas lenguas originarias (Solís 2009: 317; Napurí 2018: 192; Emlen 2016; Mayer y Sánchez 2016; Sánchez y Mayer 2018), en particular del quechua, usado en la época de las misiones como lengua franca (García [1987] 2015: 5; Marticorena 2010) ${ }^{1}$, sobre todo en la actual región Loreto.

En años recientes, han aparecido diversos trabajos relacionados con el denominado castellano amazónico, español peruano

\footnotetext{
1 Vallejos (2014: 427) señala que, en los últimos años antecedentes a la expulsión de los jesuitas (1767), en algunas zonas, también se emplearon con la misma finalidad el omagua y el kukama, de la familia tupí-guaraní. Pérez Falcón (2015: 29-30), por su parte, asevera que, en las crónicas de los franciscanos, no se hace ninguna referencia al empleo del quechua como lengua franca y sí se menciona el uso del castellano, subrayando, sin embargo, los escasos resultados de esta imposición.
} 
amazónico o PAS, acrónimo del inglés Peruvian Amazonian Spanish, según sea el caso (Jara Yupanqui 2012; Jara y Valenzuela 2013; Vallejos 2014; García 2016)2.

Pese a ello, no está demás señalar que, debido a la inmensidad de la región amazónica, algunas de las principales investigaciones sobre el tema prefieren restringir el objeto de estudio a las mayores áreas urbanas de la región, en particular, a la ciudad de Iquitos (Barraza 1998; Pérez Falcón 2015); a situaciones peculiares, como los casos de migración de habitantes indígenas amazónicos en contextos ciudadanos (Falcón 2012; Falcón, Chumbile, Canturín 2012)3; o a uno solo de los departamentos del área amazónica, como el caso del español loretano (Loretan Spanish, LS) (Jara Yupanqui 2012). En contraste, también existen trabajos que intentan ensanchar la mirada hacia un panorama unificador, centrándose en el aspecto léxico (Chirif 2016; Castonguay [1987] 2015) o abordando la cuestión desde un punto de vista diacrónico (Ramírez 2003; Arroyo 1977; Marticorena 2010).

En efecto, durante los primeros siglos de presencia española en el Perú, la ocupación territorial de la región amazónica y la difusión del castellano resultaron de mucha dificultad, hasta por lo menos la segunda mitad del siglo XIX, y los gobiernos de Ramón Castilla y Rufino Echenique, que emprendieron políticas de colonización en la selva (Varese 1973: 228; Santos-Granero y Barclay 2002: 30; Escobar 1978: 73); y, sobre todo, hasta la explosión del boom del caucho, momento en el que "el castellano aparece en la selva como una explosión, bruscamente, sin prehistoria. [...] inútil buscar la sucesión gradual. No la hay. [...] El fenómeno del castellano es una «epifanía» sin «navidad». Es una erupción súbita de un volcán

\footnotetext{
2 Jara Yupanqui (2012) centra su investigación en el español de Loreto y, en particular, en los hablantes de la ciudad de Iquitos. Por su parte, el trabajo de Jara y Valenzuela (2013) aborda la variedad rural del español hablado por los indígenas del pueblo de Jeberos (Loreto). Por otro lado, Vallejos (2014) estudia a diez hablantes monolingües de Iquitos y de tres comunidades kukama de la región. Por último, la tesis de doctorado de Miguel García (2016) se centra en los rasgos entonacionales del español hablado en la ciudad de Pucallpa (Ucayali).

3 Ambos trabajos se refieren a la variedad hablada por hablantes bilingües shipiboespañol y ashaninka-español.
} 
lingüístico que entra en actividad" (Arroyo 1977). A partir de esa expansión, el castellano se difundió rápidamente, sobre todo en el contexto urbano y en las comunidades ribereñas. Esto le permitió extenderse a lo largo del siglo XX, gracias, también, a una mayor facilidad en las conexiones espaciales y a la difusión de los medios de comunicación masiva. Incluso, ingresó a los rincones más alejados del interior de la selva.

\section{Paiche}

Paiche es una novela realista ambientada en la Amazonía peruana que describe la cotidiana lucha por la supervivencia de un grupo de hombres que intenta escaparse de la llegada del capitalismo a la selva (Pau 2017; 2019). Dentro de ese contexto, surge una comunidad socialista que llamarán, justamente, Paiche 4 .

A partir de la introducción al lector, Calvo de Araújo aborda la temática lingüística con estas palabras:

En "Paiche”, Novela Amazónica, se emplea un lenguaje esencialmente onomatopéyico, en el cual la gramática íntegra parece haber entrado en conflicto con el modo de expresarse del hablante de nuestro Oriente Verde, un lenguaje en el que aparecen palabras quechuas o similares, así como dialectos de la región y otras jergas propias del habla selvática; por ello se encontrará, en los diálogos, el modo exacto en que el selvícola se expresa, excepto cuando lo hace el protagonista que actúa en primera persona.

Por último, en lo referente a la flora, fauna, tanto terrestre como acuática, así como a los objetos propios de dicha parte de nuestro Perú, se ha empleado sus nombres peculiares, que muchas veces no

\footnotetext{
4 El afán por una existencia en equilibrio entre los seres humanos y la naturaleza fue una constante a lo largo de la vida del autor, quien "después de una carrera llena de reconocimiento internacional, se asienta en la Amazonía donde decide vivir aislado de la 'civilización', formando una comunidad de relaciones equitativas entre hombres y mujeres trabajadores que llevó el nombre de Shapshico, pero la utopía no duró mucho pues Calvo enfermó de gravedad y tuvo que ser trasladado a Lima, donde finalmente murió el 21 de octubre de 1970” (Bendayán 2014: 270).
} 
tienen equivalente en nuestro idioma. Por ello, se habrá de recurrir con frecuencia al vocabulario que aparece en la última parte de este libro (Calvo 2012: 4) .

Hay que resaltar, al interno de estas pocas líneas, varios elementos: en primer lugar, la referencia a las onomatopeyas, muy frecuentes al interior del texto; en segundo lugar, la alusión a la que el autor llama "gramática íntegra”, con la que parece indicar no solo la gramática normativa del castellano estándar, sino también su sistema fonológico. Cabe subrayar, en tercer lugar, la mención al quechua y a los demás “dialectos" de la región: con ese vocablo, el autor se refiere, presumiblemente, a las otras lenguas indígenas presentes en la selva, empleando un término sociolingüísticamente no adecuado o, tal vez, el autor demuestra a nivel inconsciente la falta de diferencia entre dialectos y lenguas. Empero, es posible también que, de esta forma, Calvo sugiera una jerarquía lingüística en el espacio amazónico, en la que el castellano se vuelve la principal y más importante forma de comunicación, en tanto que se relegan a un segundo plano las lenguas autóctonas. Esto se podría ver reflejado, también, a nivel léxico, debido a que aparecen términos que pueden resultar ininteligibles para los lectores hispanohablantes no amazónicos, quienes tendrán que acudir al vocabulario situado al final de la obra, donde se explican poco menos de seiscientas entradas. ${ }^{6}$ Estas palabras, en la mayoría de los casos, proceden justamente de lenguas indígenas. Calvo, al afirmar que no tienen equivalente en "nuestro idioma", parece excluirlas de lo que considera el vocabulario del castellano amazónico.

Finalmente, Calvo de Araújo expresa su propósito mimético: sus personajes hablan del "modo exacto en que el selvícola se expresa", pero, a la vez, aclara desde el principio que su protagonista, Sojo Arimuya, que tiene también la función de narrador intradiegético, habla de una forma distinta a los demás, lo que permite la presencia de varios idiolectos al interior de la obra.

5 Todas las citas del texto se han extraído de la edición publicada en 2012 por Petroperú S.A. El acceso a la edición princeps de 1963 fue posible tan solo al final de la redacción del presente trabajo, pero ha dado la posibilidad de encontrar varios errores al interior de la edición más reciente: el más saltante es la omisión de dos enteras líneas a la página 178, que corresponde a la página 179 de la primera edición.

6 Exactamente, quinientas noventa y uno. 


\section{Aspectos fonéticos}

Emprender un análisis fonético de un texto escrito podría parecer contradictorio y fuera de contexto. Sin embargo, la escritura de Calvo de Araújo proporciona claros ejemplos de la forma de hablar de los y las habitantes de la selva amazónica peruana, tanto a nivel fonológico como de las principales características entonacionales. La ortografía de los discursos directos de la mayoría de los personajes resulta ser, en efecto, casi fonémica, lo que ocasiona, en algunos casos, una difícil comprensión de los enunciados. Valga como ejemplo una frase pronunciada por Doña Antu, una anciana mujer cuya habla destaca como una de las más peculiares de todo el universo de personajes de la novela:

- ¡Ay! Mey estado olbidando de contarles una cosa -agregóPoes en el montes están cofiendo aguaje y hungurahui hartos hombres y aura sián ido con ellos nueve muferes, dizqué a traer callamba. Poes ahí sia ido la buchizapa, la Cipriana, sus querida poes del Fan y del Shupingahua; sia ido la Fulia y la Isidora (Calvo 2012: 175) [la cursiva es nuestra].

A nivel vocálico, una de las características más frecuentes es la alternancia de los fonemas posteriores medio /o/ y alto $/ \mathrm{u} /$, tanto al interior como a final de palabra, posiblemente por influjo del sistema vocálico quechua (Marticorena 2010: 53; Escobar 1978: 33) o de otras lenguas indígenas amazónicas. Véanse, por ejemplo, los numerosos casos de poes o de su variante poés en lugar de "pues"; incluso, el ejemplo de coalquer, coalquera o coalesquera, en sustitución de los indefinidos 'cualquier/a' y de sus relativos plurales (Calvo 2012: $89,139,175,222$, etc.). En este último ejemplo, resalta, además, la presencia de otro elemento muy frecuente en el texto: la monoptongación del diptongo creciente-ie-, (en particular después del sonido oclusivo velar sordo $[\mathrm{k}])$, con la supresión del elemento semivocálico (Marticorena 2010: 52-53). La mayoría de las ocurrencias de este fenómeno aparecen en lugar de las formas irregulares del verbo

7 Véase el apéndice A para un listado exhaustivo de las ocurrencias. 
'querer' y del interrogativo 'quién'. Un fenómeno muy parecido es la monoptongación de /ue/, que acontece, principalmente, después del sonido labiodental [f] (Marticorena 2010: 52).

El caso contrario es la creación de diptongos crecientes a partir de vocales simples (Marticorena 2010: 51-52), fenómeno que ocurre regularmente antecedido por sonidos consonánticos: la asimilación y el intercambio de la fricativa velar $/ x /$ con la fricativa labiodental /f/ y viceversa, que en la forma oral se neutralizan en una fricativa bilabial sorda $/ \phi /$.

Efectivamente, la presencia de $/ \phi /$, que asemeja casi a un soplo en la elocución, es uno de los fenómenos sobre el que la gran mayoría de los estudiosos concuerda (Escobar 1978: 45; Ramírez 2003; Marticorena 2010: 59-60).

En la novela, aparecen innumerables ejemplos, tanto de asimilación de /f/ en /x/, muchas veces con diptongación de la vocal siguiente, como, aún más numerosos, los casos opuestos, en los que la labiodental sustituye a la velar. Hace falta mencionar también el caso en el que la asimilación de la velar en labiodental se junta, además, con la monoptongación del diptongo siguiente: el ejemplo más recurrente es el del nombre propio 'Juan' que, en las palabras de los personajes de la novela, aparece como Fan (Calvo 2012: 77, 92, 134, 175, etc.).

Entre las otras características fonéticas, cabe citar por lo menos la frecuente inserción del fonema aproximante palatal sonoro /j/ al interior (epéntesis) y a final de palabra (epítesis) (Marticorena 2010: 62). La inserción epentética acontece, principalmente, en medio de hiatos formados por dos vocales abiertas. La epítesis, por su parte, se encuentra con frecuencia a final de la primera persona del verbo 'saber' y del auxiliar 'haber' en el pretérito perfecto. Para recrear la hipoarticulación prosódica de los personajes, Calvo suele fundir estos verbos con los pronombres y otros elementos; en efecto, crea nuevas palabras como mey, tey, ley, lesey, leide ${ }^{8}$ (Calvo 2012: 121, 164, 189, 212, 27, etc.).

8 'Me he', 'te he', 'le he', 'les he', 'le he de'. 
La unión de palabras simples con la asimilación de algún fonema de la primera palabra es otra de las características del habla de los personajes en Paiche (Marticorena 2010: 71). En la novela, hay diversos ejemplos de palabras resultantes de la fusión de un elemento pronominal y un verbo, con la reducción silábica procedente de la eliminación del hiato que se crearía entre la última letra de la primera palabra y la primera de la segunda9.

Un caso similar ocurre con la formación de palabras resultantes de la unión de dos palabras con la eliminación de algún fonema, normalmente de la primera (Marticorena 2010: 71). En la novela, esto pasa, principalmente, con la forma 'dice que', con apócope de la -e- final del verbo, como en los casos dizque, disqué o dizqué (Calvo 2012: 35, 57, 93, etc.) ${ }^{10}$.

La pérdida de vocales átonas en contexto intervocálico ocurre, también, al interior de palabras. El ejemplo más llamativo propuesto por Paiche es el nombre de la capital de la región Loreto, Iquitos, que se vuelve Iquitss (Calvo 2012: 38, 116, 222, etc.) en la forma de hablar de los personajes. Sin embargo, las vocales no son los únicos sonidos que suelen desaparecer en las palabras de los hablantes (Marticorena 2010: 65). De manera puntual, el adverbio 'también' es pronunciado (y trascrito) como tamién y, sobre todo, a ser suprimida es la -dfinal en palabras agudas: mitá, usté, berdá o barbaridá (Calvo 2012: $128,139,189$, etc.) son algunos ejemplos que lo atestiguan.

Cabe resaltar, finalmente, que en la novela se observa una frecuente alternancia ortográfica entre -b- y-v-, con la neta preponderancia de palabras que por etimología tendrían una -v-, escritas en cambio con -b-. Esta elección del autor delata otra de las características de la fonética del castellano amazónico: el mantenimiento del sonido oclusivo, incluso en los contextos de posible aparición

\footnotetext{
9 Véase los siguientes casos: mian, tia o sian (Calvo 2012: 63, 170) en lugar de 'me han', 'te ha' o 'se han'; o también sinunda (p. 72) por 'se inunda', bastar (p. 105) en lugar de 'va a estar', diuna (p. 156) en vez de 'de una' o la doble ocurrencia en sia diacer (p. 119) por 'se ha de hacer'.

10 Véase el Diccionario Panbispánico de Dudas (DPD) http://lema.rae.es/ $\mathrm{dpd} /$ ?key=dizque [Consultado el 2 de marzo de 2018].
} 
de un alófono aproximante / $\beta$ / (Hualde et al. 2010: 69; Lipski 2011: 344). En efecto, aparecen ejemplos de ocurrencia en contextos intervocálicos: una bez o bibir (2012: 189) e, incluso, después de consonante: por bibir (2012: 189). Sin embargo, este cambio aparece frecuentemente incluso en posiciones en las que normalmente tendríamos sonido oclusivo y -v- ortográfica; por ejemplo, después de una nasal, como en simbergüenzas (2012: 175), o después de una pausa, como en la primera palabra de la intervención del personaje de doña Flor en una discusión: - Boyá (2012: 175).

Para terminar la panorámica de corte fonológico, es necesario mencionar la estrategia experimentada por el autor para transferir en la página escrita la musicalidad típica de la entonación amazónica. Se trata, principalmente, de la geminación de las vocales en posición intermedia o final de palabra. Este simple recurso es utilizado en palabras de cualquier clase gramatical y permite una lectura con subidas y bajadas de tono, desplazamientos acentuales que recrean en la mente del lector la peculiar prosodia de las y los hablantes de la selva ${ }^{11}$.

\section{Aspectos morfosintácticos}

Una de las características morfológicas más llamativa del castellano del Perú es el empleo difundido de los diminutivos ${ }^{12}$, no solo para nombres y adjetivos, sino también para elementos pertenecientes a clases gramaticales supuestamente invariables (Ramírez Luengo 2016: 112). El castellano hablado en la selva amazónica peruana no se escapa de esta tendencia y la novela de Calvo de Araújo nos proporciona un largo listado de diminutivos que van desde los canónicos sustantivos, pasando por los adjetivos calificativos y llegando a verbos en gerundio, adverbios y numerales ${ }^{13}$. El origen de este uso

\footnotetext{
11 "Yo no quisiera deeecirle que queremos descaaansar ahora, yo...y don Panduro; pero...es que harto ha dolido el Sol y todo nuestro cueeerpo está malogrado" (Calvo 2012: 179) [La cursiva es nuestra].

12 Como señala A.M. Escobar (2000), su uso extendido también es característico del español del altiplano central de México (Lope Blanch 1983: 161) y del espacio andino, no solo peruano, sino también de Bolivia (Ramírez Luengo 2016).

13 Véase el Apéndice B para un listado exhaustivo de las ocurrencias.
} 
tan difundido podría deberse al contacto con el quechua (Godenzzi 1996; Escobar 2000) y al frecuente empleo que en esta lengua se hace del sufijo -cha, utilizado tanto para indicar tamaño reducido como para expresar significado de afecto y modestia (Escobar 2000). A pesar de que la marca más productiva para la formación de diminutivos es -ito/a, cabe subrayar las numerosas ocurrencias del morfema -illo/a (Marticorena 2010: 73), muchas veces con la transformación de la vocal final del masculino en -u, en particular con sustantivos de origen quechua como buambrillu, 'niño' (Calvo 2012: 90, 212, etc.).

Las uniones de morfemas léxicos quechua ${ }^{14}$ con otros gramaticales castellanos (y viceversa) representan, posiblemente, el fenómeno morfológico más interesante del castellano amazónico. En este caso, Paiche recoge y presenta varios ejemplos. A pesar de que los verbos son la clase más productiva en este sentido, se tiene, también, varios ejemplos de sustantivos y adjetivos.

Los casos contrarios en los que un lexema castellano se une a un morfema quechua son muchos menos y resaltan los que presentan el sufijo aumentativo, con un matiz burlesco, sapa o zapa. Un significado parecido al de sapa es el del sufijo aumentativo castellano -azo/a ${ }^{15}$, que es muy recurrente tanto con adjetivos, grandazo o buenazo, como con sustantivos, otorongazo o solazo, e incluso con algún adverbio, como lejazos (Calvo 2012: 64, 65, 79, 180, 121).

Otra de las características indicadas por Marticorena propias del castellano amazónico, que es recurrente en la novela, es la creación de verbos denominales, principalmente a través del sufijo -ear y de sus relativas formas conjugadas.

\subsection{Posesivos y "discordancia” nominal}

Como señala Vallejos (en evaluación), uno de los rasgos más característicos del español amazónico es la posible discordancia de número en las frases nominales. En el castellano estándar, en efecto, el adjetivo posesivo concuerda con lo poseído, sin importar que

\footnotetext{
14 O en otra lengua indígena.

15 Marticorena (2010: 72) lo transcribe como -aso/a.
} 
el poseedor sea único, múltiple, humano, animado, no-animado o abstracto. En el castellano amazónico, esto no es necesariamente vinculante, puesto que —además de los mayoritarios casos de concordancia- es relativamente frecuente la ocurrencia de un adjetivo plural y un sustantivo singular ${ }^{16}$, por ejemplo, sus ropa. Tanto el estudio de Vallejos (en evaluación), como uno antecedente de Barraza de la Cruz (1998), llegan, a través de un cuidadoso análisis de corpora seleccionados, a la misma conclusión: la falta de concordancia es determinada en la mayoría de los casos por la presencia de un poseedor múltiple, es decir que los poseedores son varios y el adjetivo posesivo concuerda con estos en lugar de lo poseído.

En Paiche, lo primero que llama la atención sobre este tema es el hecho de que, además de ocurrencias con adjetivos posesivos de tercera persona, se encuentran numerosos casos de adjetivos plurales de primera y segunda persona más un sustantivo en singular ${ }^{17}$ : mis palabra, tus orden o nuestras canoa (Calvo 2012: 18, 74). Por obvias razones, solamente en el último de estos ejemplos se podría suponer que la discordancia entre los dos elementos dependa del número del poseedor.

Por lo que atañe la presencia del posesivo "sus", en cambio, la tendencia señalada por Vallejos y Barraza parece confirmarse también en la novela, ya que el 62,2\% de las ocurrencias (51 sobre 82) se refiere a varios poseedores.

Continuando con la exploración del tema de los posesivos, se analizan dos fenómenos relacionados: el doble posesivo - llamado también posesivo redundante (Rodríguez Garrido 1982) o posesivo enfático (Escobar 1978: 108) — y la inversión del genitivo (Vallejos 2014: 443). El doble posesivo "consiste en el empleo de un posesivo ante un sustantivo cuyo posesor está además indicado por un complemento de preposición más nombre (p. e.: su casa de Juan), frente a la forma del castellano estándar que utiliza el artículo en el lugar

\footnotetext{
16 Como señala la misma Vallejos (2014; en evaluación) la cuarta posibilidad (adjetivo singular - nombre plural) no suele ocurrir.

17 Se han identificado en total 114 ocurrencias de discordancia, de las que 20 presentan el adjetivo “mis"; 10 “tus”; 1 “nuestros”, 1 “nuestras” y 82 “sus”.
} 
del posesivo (la casa de Juan)” (Rodríguez Garrido 1982: 117). La existencia de esta estructura se registra no solo en la Amazonía, sino también en los Andes (tanto al sur, Ayacucho, como en la sierra norte). Algunos lingüistas (Escobar 1978; Pozzi-Escot 1973) imputaban la existencia del doble posesivo al influjo de la morfosintaxis quechua. Sin embargo, Rodríguez Garrido (1982), reconociendo la importancia del contacto entre las dos lenguas, define esta peculiaridad como un arcaísmo; asimismo, proporciona ejemplos de obras españolas clásicas (entre ellas El Cid y La Celestina).

Por su parte, Napurí (2018), en su trabajo sobre la presencia del doble posesivo en dos variantes de español amazónico con sustrato respectivamente bora y asháninka, señala la importancia de la gramática de la lengua de sustrato para la aparición del doble posesivo. En Paiche, se encuentran numerosos casos: sus tela de la araña, sus ojo del muchacho, su mufer de varios (2012: 155, 222) y llama la atención que en muchos casos esta construcción sirva para indicar ubicación: en su ladito del tigre, en su tras de los guardias, en su adebajo de mis rodilla (2012: 18, 189, 201). Se encuentra, además, un caso que escapa parcialmente de la norma de la "anormalidad". En efecto, a pesar de ser, generalmente, exclusivo de la tercera persona, se tiene un ejemplo, tu yerno de ustéd (2012: 232), en el que aparece un posesivo de segunda persona que no concuerda con el pronombre personal sucesivo de tercera. Relacionado al doble posesivo es el fenómeno de la inversión de sus constituyentes, como acontecería invirtiendo uno de los ejemplos antecedentes, que se transformaría en de la araña sus tela. Esta construcción tampoco es exclusiva del español amazónico, como señala Germán De Granda (1997) en su trabajo sobre el español andino peruano, y — tomada en cuenta la inexistencia de estructuras similares en la lengua española histórica - se debería a "la aplicación de las reglas de formación de sintagmas posesivos existentes en la lengua quechua (y en la aimara)" (De Granda 1997: 143). Sin embargo, la estructura es percibida, sobre todo, fuera del ambiente amazónico, como uno de los trazos típicos del castellano amazónico. Vallejos menciona que la inversión del genitivo, junto con los rasgos entonacionales, 
es el principal elemento usado por los medios de comunicación para representar al "castellano charapa" de forma estereotípica (2014: 445-446). A pesar de esto, la estudiosa señala que, en su caso de estudio, esta estructura es poco frecuente.

La novela de Calvo de Araújo confirma los planteamientos lingüísticos de Vallejos: de los 23 casos de doble posesivo, tan solo dos presentan la inversión de los elementos: del barbasco hace mal su polvo y iAquístá del shuyo sus caminooo! (Calvo 2012: 57, 89).

Para terminar con los posesivos, señalamos finalmente el empleo de la construcción [posesivo + adjetivo] en lugar de [posesivo + sustantivo], como en su largo, su joven, sus desnudo (Calvo 2012: $128,135,145)$. Para volver a la falta de concordancia, además de los casos ya señalados, cabe mencionar algunas construcciones que, en su hora, Inés Pozzi-Escot (1972) había señalado como típicas del castellano de Ayacucho y que se presentan también en el castellano amazónico. Estamos hablando de la discordancia de género y número entre [nombre + adjetivo], y entre [artículo + nombre], además de la falta de concordancia de [número + persona] entre sujeto y verbo principal en una oración ${ }^{18}$. Véanse como ejemplo los casos siguientes: plátanos asado, las pobre, el sueños, usté eres, usté sabes $(2012: 33,78,114 ; 155)$.

\subsection{Otras peculiaridades sintácticas}

Otro fenómeno relacionado con estructuras que no se corresponden a otras variedades del castellano es el de la alteración de los constituyentes al interior de una oración. En efecto, el orden canónico SVO es frecuentemente modificado en los enunciados emitidos por los personajes de la novela. Recurre a menudo la posposición del verbo como último elemento de la oración, tanto en oraciones afirmativas: usté poes todo nomás cuidas (Calvo 2012: 94), harto animal hay (Calvo 2012: 65), como en interrogativas directas: ¿tan ferte poes ese beneno es? (Calvo 2012: 155). Empero, aparecen en el texto

\footnotetext{
18 En particular, entre el pronombre usted y el verbo, conjugado a la segunda persona singular (Marticorena 2010: 95).
} 
numerosos casos de posposición del sujeto, como, por ejemplo, están boqueando los shuyos (Calvo 2012: 85) o está espumoso el río. Estructuras de estos tipos reflejarían, según Marticorena (2010: 93), la organización sintáctica del quechua, quien señala la frecuencia con la que en el castellano amazónico se utiliza la perífrasis verbal formada por las formas del verbo "haber" más la preposición "de" más un infinitivo. Según el autor, este tipo de oración corresponde a una imperativa que sustituye la más común: "tener que + infinitivo". Paiche proporciona diversos ejemplos de este uso ${ }^{19}$, pero, en numerosos casos, esta perífrasis tiene más sencillamente un significado de acción futura (correspondiente a la forma “ir a + infinitivo”) ${ }^{20}$.

Finalmente, cabe mencionar algunas expresiones que también son percibidas como peculiares del habla amazónica: en primer lugar, la palabra "di”"21, utilizada con función adverbial en oraciones interrogativas, para pedir corroboración o validación de una aseveración ${ }^{22}$ y, en segundo lugar, el empleo de la expresión “ya vuelta”, que, como explica Alberto Chirif (2016: 303) en su diccionario, puede implicar interrogación o sorpresa con el sentido de 'otra vez' o 'nuevamente', pero, también, admiración e incredulidad ${ }^{23}$.

\section{Conclusiones}

El análisis de la caracterización, tanto fonética como morfosintáctica, del castellano amazónico en la novela Paiche permite adentrarse en la cuestión de la variación lingüística y reconocer la multiplicidad y la heterogeneidad del castellano en las distintas regiones del mundo hispanohablante, y en la misma región amazónica peruana.

\footnotetext{
19 Para citar algunos: "has de traer" (2012: 29), “sia diacer” (2012: 99), "les hey de decirles” (2012: 29, 99, 131).

20 Véase el DPD http://lema.rae.es/dpd/?key=haber [Consultado el 2 de marzo de 2018].

21 El fenómeno no es exclusivo de la región amazónica, sino que es en general norteño. Se agradece a uno de los revisores por la señalación.

22 Véase: “seguro queas de estar contento, ¿di?”, “será bueno jurgonearle, ¿di?” (2012: $138,168)$

23 “¡Qué ya buelta te pasa!”, “¡Ya buelta, doña Rosaura! [...] Eso ya buelta dices...” (2012: 91, 155).
} 
Cabe reflexionar, sin embargo, sobre las razones de la elección lingüística de Calvo de Araújo, quien sintetiza en el habla de sus personajes las marcas más características de las diversas variedades del castellano amazónico. Parece útil, por ende, volver a citar una parte de la introducción al lector, en la que el autor afirma que en la obra "se encontrará, en los diálogos, el modo exacto en que el selvícola se expresa” (Calvo 2012: 4). Calvo de Araújo, así, al interior de un más amplio proyecto narrativo realista, apunta hacia una representación verosímil del mundo amazónico y la lengua adquiere un rol de primaria importancia puesto que imita, de la forma más fiel posible, la manera de expresarse de la población amazónica peruana. De manera diferente respecto a autores como José María Arguedas, quien buscó a lo largo de toda su experiencia una síntesis entre códigos distintos y la respuesta a la pregunta " ¿En qué idioma se debía hacer hablar a los indios en la literatura?” (Arguedas 2011: 19), la atención del autor en Paiche se centra solo tangencialmente en la población indígena, en tanto vuelve la mirada hacia los sectores mestizos de la sociedad. Si es cierto que Arguedas (sobre todo en sus obras más tempranas) había propuesto una lengua "recreada" de forma casi artificial (Escobar 1984; Arguedas 2011), Calvo de Araújo no necesitó crear una "ficción" lingüística, sino tan solo recoger miméticamente la forma de hablar de los ribereños amazónicos. Lo que resulta significativo señalar es la finalidad última que subyace a este afán realista. ¿Se trata de meras razones expresivas y estéticas? La respuesta parece ser negativa. En efecto, cabe recordar que la novela, a pesar de haber sido publicada tan solo en 1963, fue escrita por el pintor a comienzos de los años 40; es decir, en la etapa de la novela indigenista peruana. Con esta corriente literaria, Paiche comparte las finalidades de reivindicación social y política, que se contraponen a la perspectiva de los sectores hegemónicos de la sociedad. Asimismo, el empleo de la peculiar forma de hablar de la selva se inserta en un proyecto de mayor alcance que tiene que ver con la valorización misma del espacio amazónico (y de sus moradores), cuya percepción ya se había cristalizado en el mito del "infierno verde". Calvo de Araújo, de esta forma, gracias también al 
lenguaje, contribuye a reivindicar la identidad amazónica, desmi(s) tificando el imaginario sobre la Amazonía y presentando una realidad menos estereotipada y más objetiva.

\section{Referencias bibliográficas}

Arguedas, José M.

2011 "La novela y el problema de la expresión literaria en el Perú". En Yawar Fiesta. José María Arguedas. Lima: Editorial Horizonte, 13-20.

Arroyo, José M.

1977 "Nota sobre el habla de Loreto". Conocimientos. Revista de la Universidad Nacional de la Amazonía. 1, 3, 7-12.

Barraza De La Cruz, Yris

1998 Apuntes sobre gramática del castellano de Iquitos. Tesis de posgrado. Lima: UNMSM

BENDAYÁn, Christian

2014 "El arte de un pueblo sin tiempo". En Iquitos. Eds., Rafael Varón Gabai y Carlos Maza. Lima: Telefónica, 268-77.

Calvo de Araújo, César

2012 Paiche. Iquitos: PetroPerú.

Castonguay, Louis

[1987] 2015 Vocabulario regional del Oriente Peruano. Iquitos: Ceta.

Chirif, Alberto

2016 Diccionario Amazónico. Voces del castellano en la selva peruana. Lima: Lluvia editores/ Caaap.

De Granda, Germán

1997 "Replanteamiento de un tema controvertido: Génesis y retención del doble posesivo en el español andino”. Revista de Filología Española. 77, 139-147. https://doi.org/10.3989/ rfe.1997.v77.i1/2.368

EmLen, Nicholas Q.

2016 "Multilingualism in the Andes and Amazonia: A View from In-between: Multilingualism in the Andes and Amazonia". 
The Journal of Latin American and Caribbean Antbropology. 22, 3, 556-577. https://doi.org/10.1111/jlca.12250

EsCOBAR, Alberto

1978 Variación sociolingüística del castellano en el Perú. Lima: IEP. 1984 Arguedas o la utopía de la lengua. Lima: IEP.

EsCOBAR, Ana M.

2000 Contacto social y lingüístico. El español en contacto con el quechua. Lima: Fondo editorial PUCP.

Falcón CCenta, Pedro M.

2012 "Características del léxico verbal en el castellano de los indígenas bilingües amazónicos”. Lengua y Sociedad. Lima: Instituto de Lingüística Aplicada. 12, 1, 141-152.

Falcón Pedro, Rocío Chumbile y Jhon Canturín

2012 "Características morfosintácticas del castellano amazónico en hablantes indígenas bilingües en Lima”. Escritura y Pensamiento. XV, 30, 79-112.

García, Joaquín

[1987] 2015 “Nota de los editores”. Castonguay, 5-6.

García, Miguel

2016 The intonational patterns of the Peruvian Amazonian Spanish. Rising Accents an Segmental Factors. Tesis doctoral. Columbus: The Ohio State University.

GodenZZi, Juan C.

1996 "Transferencias lingüísticas entre el quechua y el español”. Signo y Seña. 6, 73-99.

Hualde, José I. et al.

2010 Introducción a la Lingüística Hispánica. New York: Cambridge University Press.

JARA YUPANQUi, Margarita

2012 "Peruvian Amazonian Spanish: linguistic variation, language ideologies and identities". Sociolinguistic Studies SOLS. 6, 3, 445-469.

Jara Yupanqui, Margarita y Pilar Valenzuela

2013 "El uso del perfecto en secuencias narrativas en el español peruano amazónico: el caso de Jeberos”. Lexis. XXXVII, 1, 33-70. https://doi.org/10.1558/sols.v6i3.445 
LIPSKI, John

2011 El español de América. Madrid: Cátedra.

Lope Blanch, Juan (ed.)

1983 Estudios sobre el español de México. México: Universidad Nacional Autónoma de México.

Marticorena, Manuel

2010 El castellano amazónico del Perú. Iquitos: Instituto de Investigaciones Educativas e Históricas de la Amazonía Peruana.

MAYer, Elisabeth y Liliana SÁNCHEZ

2016 "Object agreement marking and information structure along the Quechua-Spanish contact continuum". Revista Española de Lingüistica Aplicada/Spanish Journal of Applied Linguistics. 29, 544-581.

NAPURí, Andrés

2018 "Eso era mi meta de mí el doble posesivo en dos variedades de español amazónico”. Lexis. XLII, 1, 191-205. https://doi. org/10.18800/lexis.201801.008

PAU, Stefano

2017 "Modelos para la superación de la crisis del sistema capitalista: Paiche y E venne il sabato, novelas amazónicas". Revista de Critica Literaria Latinoamericana. XLIII, 86, 277-300.

2019 “Más allá del 'infierno verde’ y del 'paraíso perdido'. Paisaje y perspectiva medioambiental en dos novelas amazónicas peruanas”. En América: el relato de un continente. Eds., Susanna Regazzoni y Fabiola Cecere. Venezia: Edizioni Ca'Foscari, 107-122.

Pérez Falcón, Thatiana

2015 El adverbio en el castellano de Iquitos. Tesis de licenciatura. Lima: Universidad Nacional Mayor de San Marcos.

Pozzi-Escot, Inés

1972 "El castellano en el Perú: norma culta nacional versus norma culta regional". En El reto del multilingüismo en el Perú. Comp., Alberto Escobar. Lima: IEP, 123-142.

1973 Apuntes sobre el castellano de Ayacucho. Lima: Universidad Nacional Mayor de San Marcos. 
RAMírEZ, Luis H.

2003 El español amazónico hablado en el Perú. Hacia una sistematización de este dialecto. Lima: Juan Gutemberg Editores.

Ramírez Luengo, José L.

2016 "El diminutivo en la Bolivia andina de la primera mitad del siglo XIX: valores y funciones en el Diario de J. S. Vargas”. Cuadernos de Investigación Filológicas, 42, 111-127. https:// doi.org/10.18172/cif.2969

Rodríguez Garrido, José A.

1982 "Sobre el uso del posesivo redundante en el español del Perú". Lexis. VI, 1, 117-123.

SÁNCHEZ, Liliana y Elisabeth MAYER

2018 "Typological Differences in Morphological Patterns, Gender Features, and Thematic Structure in the L2 Acquisition of Ashaninka Spanish". Languages. 3, 21. https://doi. org/10.3390/languages3020021

Santos-Granero, Fernando y Frederica Barclay

2002 La frontera domesticada. Historia económica y social de Loreto 1850-2000. Lima: Fondo editorial PUCP.

Solís FonseCA, Gustavo

2009 "Perú Amazónico". En Atlas sociolingüístico de pueblos indígenas en América Latina. Cochabamba: UNICEF y FUNPROEIB Andes.

Vallejos, Rosa

2014 "Peruvian Amazonian Spanish. Uncovering variation and deconstructing stereotypes". Spanish in context, $11,3,425-53$.

(En "Nominal possession in Peruvian Amazonian Spanish: the evaluación) role of animacy in the emergence of grammar". En Spanish Diversity in the Amazon: Dialect and Language Contact Perspectives. Eds., A. M. Escobar, R. Zariquiey, P. Valenzuela y M. Jara.

VARESE, Stefano

1973 La sal de los cerros. Lima: Retablo de Papel. 


\section{APÉNDICE A (Aspectos fonéticos)}

\section{Vocales}

1.1. Alternancia fonemas posteriores medio /o/ y alto /u/ poes (pp. 23, 63, 70, 78, 89, 90, etc.)

poés (pp. 79, 190, 201) 'pues'

aura (pp. 135, 136, 139, 141, etc.)

aúra (p. 138)

aurita (pp. 64, 91, 154, 169, etc.)

supresión

pota (pp. 92, 93, 100, etc.)

despoes (pp. 155, 175, 189, 220, etc.)

boelta (pp. 156, 175, 204, etc.)

coartel (p. 175)

coando (pp. 175, 189, 201, etc.)

$\operatorname{arigu}($ p. 109)

coalquer (p. 175)

coalquera (p. 89)

coalesquera (pp. 139, 222, etc.) 'cualquier/a', 'cualesquiera'

'ahora' y 'ahorita', (con la del grafema intervocálico -h-) 'puta' 'después'

'vuelta' 'cuartel' 'cuando' 'amigo'

\subsection{Monoptongación del diptongo creciente /ie/}

quero, queres, quere, queren, queras, quera, querendo, queréndote, queréndose quén/quen (pp. 91, 93, 145, etc.) 'quién/quien'

1.3. Monoptongación de /ue/

ferte (pp. 100, 155, 168)

fera (p. 137)

se fé (p. 222)

'fuerte'

'fuera'

'se fue'

1.4. Diptongación de vocales simples

1.4.1. /a/ $\rightarrow$ /ua/

juácil (pp. 135, 136 175, etc.)

'fácil'

juarol (p. 91)'farol' 
juastidiar (p. 79)

1.4.2. /e/ $\rightarrow$ /ue/

jueo (pp. 78, 223)

juelizmente (pp. 155, 170)

cajué (p. 33)

\section{Consonantes}

Asimilación de /f/ en /x/

bujeos (pp. 78, 101, 203, 2012, etc.) 'bufeos'

juerte/s (p. 78)

juerza (pp. 57, 78, 206, 246, etc.) 'fuerte/s'y 'fuerza'

Asimilación de /x/ en /f/

muferles (pp. 83, 100,144, 189, etc.) 'mujer/es'

cofudo/a/os/as (pp. 57,70, 134, 163, etc.) 'cojudo/a/os/as'

foben (p. 110)

viefo (p. 248)

Epéntesis /j/

beya (p. 35)

cayen (p. 78)

creyo (p. 86)

meyar (p. 201)

2.4. Epítesis /j/

sey (pp. 144, 154, etc.)

sei (pp. 57, 83)

hei (pp. 57, 64, etc.)

bey (pp. 66, 110)

\section{Entonación}

bostezaaando (p. 118)

lejaazos (p. 120)

raaatooo (p. 125)

escucháaaando (p. 125)

escondiéeeeendose (p. 125) 'fastidiar'

'feo'

'felizmente'

'café' 'joven'

'viejo'

'vea'

'caen'

'creo'

'mear'

'sé'

'he' 
APÉNDICE B (Aspectos morfosintácticos)

\section{Diminutivos}

\subsection{Sustantivos}

platanito; dedito; purmita; barbasquito; masatito; guineitos; boita; pejecito (pp. 85, 170; 85; 177, 203, 91)

\subsection{Adjetivos}

clarito; calladito (pp. 139, 204)

\subsection{Verbos}

llegandito (p.175)

\subsection{Adverbios}

enseguidita; apenitas; antesito; casito y casisito; nunquita; ashishito ${ }^{24 ;}$ aquicito y allacito; arribita (pp. 95, 149, 74, 79, 221, 222, 81, 85, 180, 215)

\subsection{Numerales}

unito; dosito (pp. 87, 221)

2. Unión de lexemas quechua con morfemas gramaticales castellanos

\subsection{Verbos}

mitayar (p. 29)

'cazar' $\rightarrow$ del sustantivo quechua mit'a

pishtar (p. 33)

'degollar' $\rightarrow$ de pistay

llullampear (p. 203) 'mentir' $\rightarrow$ de llulla

tacllándole (p. 223) 'acariciándole' $\rightarrow$ de t'aqllay

2.2. Sustantivos

mullacal (p. 125)

uchitu

'bosque de mullak'

'ajî' $\rightarrow$ de $u c h u$ con sufijo diminutivo

${ }^{24}$ Del adverbio así, con un sonido fricativo postalveolar sordo [ $]$ ]. 
2.3 Adjetivos

pacucho (p. 70) 'rubio' $\rightarrow$ de paqu más el sufijo derivativo -ucho

ismatero (p. 76) 'cagón' $\rightarrow$ de isma, heces, con sufijo -(t)ero

3. Unión de lexemas castellanas con morfemas gramaticales quechua buchizapa (p. 175)

barrigasapa (p. 204) 'barrigudo/a'

pollerazapa (p. 176)

capazapa (p. 189) 'el que lleva una gran sotana' (cura)

4. Creación de verbos denominales con el sufijo -ear

tarrafear (p. 205) 'pescar con tarrafas (redes)'

anzuelear (p.11) 'pescar con anzuelos'

leñear (p. 57) 'cortar leña'

macheteado (p. 155) 'cortar con un machete'

charapear (p. 88) 'capturar tortugas charapas'

zancudeaba (p. 67) 'alejar y matar zancudos'

cofudean (p.67) 'engañar'

brujeado (p. 70) 'hechizar'

Recepción: 14/03/2018

Aceptación: 02/06/2019 